\title{
Analysis of Changes in Biological Soil Crusts Using Landsat Image Time Series for the Southern California Desert
}

\section{Potter $\mathrm{C}^{1^{\star}}$ and Weigand $\mathrm{J}^{2}$}

${ }^{1}$ NASA Ames Research Center, Biospheric Science, Moffett Field, California, USA

${ }^{2}$ Bureau of Land Management (BLM), United States Department of the Interior, Sacramento, California, USA

*Corresponding author: Chris Potter, NASA Ames Research Center, Biospheric Science, Moffett Field, California, USA, Tel: 650-604-6164; Email: chris.potter@nasa.gov

Received date: Mar 26, 2016; Accepted date: Apr 21, 2016; Published date: Apr 28, 2016

Copyright: (C) 2016 Potter C, et al. This is an open-access article distributed under the terms of the Creative Commons Attribution License, which permits unrestricted use, distribution, and reproduction in any medium, provided the original author and source are credited.

\begin{abstract}
Developers of renewable energy installations in Southern California must monitor the impacts of operations of new facilities on fragile desert ecosystems. This study is the first to use Landsat satellite spectral data to map changes in the distribution of biological soil crusts (BSCs) across federal lands of the Lower Colorado Desert. The coverage of BSCs comprising $>33 \%$ pixel area totaled $4008 \mathrm{Km}^{2}$ in 1990 , and increased to $4841 \mathrm{Km}^{2}$ by 2014 . The proximity of changing areas of BSC cover between 1990 and 2014 to known river flow channels such as the Lower McCoy Wash, Riverside County, CA) implied that flash floods associated with heavy precipitation events are important agents of change for BSC cover. These results have an immediate application for mapping the potential impacts of flash flood events around developed urban areas and utility-scale solar energy installations in the deserts of Southern California.
\end{abstract}

Keywords: Biological soil crust; Landsat; Lower Colorado desert; California

\section{Introduction}

Knowledge of the ecological roles of biotic soils crusts (BSCs) in arid lands has advanced greatly over the past several decades and has transformed how managers of desert ecosystems understand biological processes that stabilize and fertilize desert soils [1]. Nonetheless, management focused on conservation of BSCs to promote robust desert ecosystem functioning in the Mojave and Colorado Deserts of California is not widely practiced, in part because the abiotic and biotic factors affecting soil biotic crusts and stages of crust development remain poorly understood [2].

Belnap et al. [3] reported that BSCs formed preferentially on soils in the Eastern Mojave Desert having high percentages of silt, very fine sand, and fine sand, the very same soil textures most susceptible to erosion by wind. Generalizations about ecologic functions of BSCs are still difficult to make however, because of the great diversity life forms and species in soil crust communities, consisting variously of bacteria, lichens, and non-vascular plants such as mosses [4].

Pietrasiak et al. [5] reported that past disturbance intensity was inversely related to the likelihood of current presence of BSCs in the Mojave and Colorado Deserts. BSCs in these California deserts are patchily distributed and have less structural complexity and biological diversity than crust communities found in the better-studied and generally cooler Great Basin and Colorado Plateau arid lands [1,2].

Cyanobacteria and Cyanolichens are the major components of most BSC communities in Southern California deserts [6]. Cyanobacteria crusts are millimeter-thin crusts and are typically invisible to the unaided eye. They occupy only the most stable soil desert surfaces for long periods and are easily disturbed. Cyanobacteria are unique prokaryote (bacterial) organisms in that they can photosynthesize carbohydrates, as well as fix atmospheric nitrogen into compounds that enhance soil fertility for formation of amino acids and proteins in plants. Cyanolichens consist of symbiotic combinations of Cyanobacteria and ascomycete fungi (mostly in the Order Pezizales), with occasional algae species as a third component [6]. They are readily visible to the unaided eye and often have a dark, rugose (warty) appearance.

Construction at utility-scale renewable energy production facilities usually entail mechanical disturbance of desert surfaces. Information about desert soils and rates of changes to desert ground surfaces is critical in designing facilities; constructing installations, roadways, and transmission lines; restoring vegetation to sites used for temporary equipment and material storage; reducing fugitive dust emissions; and eventual decommissioning. Therefore, the main purpose of this study was to validate the range of the Biological Soil Crusts Index (BSCI) developed by Chen et al. [7] using satellite images across federal lands of the Lower Colorado Desert area for the years 1990, 2000, 2010, and 2014 , to serve as baselines of change and for future monitoring in the Desert Renewable Energy Conservation Plan [8]. One of the goals of the DRECP, developed mainly by the Bureau of Land Management (BLM), is to is to conserve and manage plant and wildlife communities in the desert regions of Southern California, while also facilitating the timely permitting of new renewable (solar and wind) energy facilities [8]. Approximately 22.5 million acres of federal and non-federal California desert land are part of the DRECP area.

\section{Study area}

The Lower Colorado Desert within the DRECP area is shown in Figure 1. The study area occupies the South-Eastern corner of California, extending from the Peninsular Ranges of San Diego and Riverside Counties in the west to the Colorado River in the east. It is the Western extension of the Sonoran Desert region of Southern Arizona and Northern Mexico [9]. 
Citation: Potter C, Weigand J (2016) Analysis of Changes in Biological Soil Crusts Using Landsat Image Time Series for the Southern California Desert. J Remote Sensing \& GIS 5: 163. doi:10.4172/2469-4134.1000163

Page 2 of 7

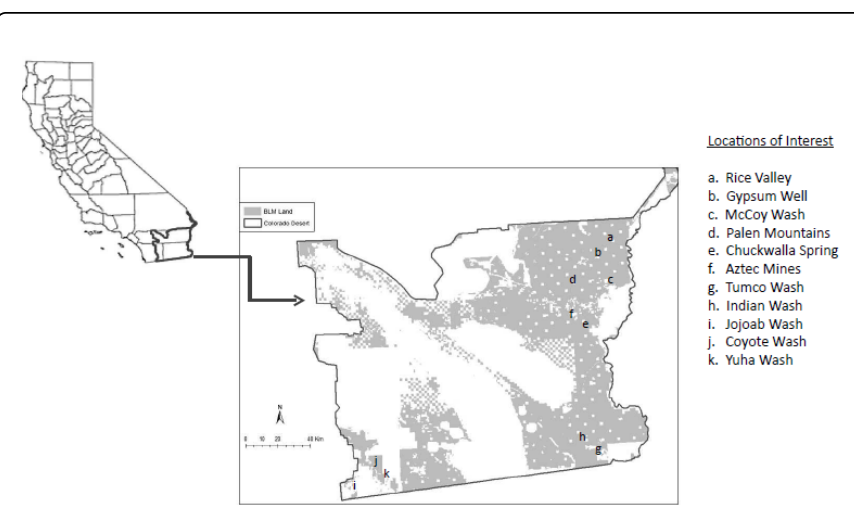

Figure 1: Study area map of the Lower Colorado Desert DRCEP lands in Southern California. The light grey shaded areas are the public lands managed by the Bureau of Land Management (BLM).

The region is uniformly arid, due in part to the strong rain shadow of the Peninsular Ranges. Annual rainfall totals are generally less than $15 \mathrm{~cm}$ and often less $10 \mathrm{~cm}$. Daily high temperatures in the summer are regularly above $40^{\circ} \mathrm{C}$ [10]. The terrain consists mostly of broad, flat valleys with widely-scattered, small mountain ranges of nearly barren rock. Runoff from seasonal rainfall has formed alluvial fans, desert arroyos, playas, desert washes, ephemeral and perennial streams, and riparian vegetation communities [11]. Vegetation cover in the valleys is dominated by low shrubs, primarily creosote bush (Larrea tridentata) and white bursage (Ambrosia dumosa) [9].

\section{Methods}

\section{Landsat image processing}

Landsat images acquired from United States Geological Survey (USGS) were processed to detect the changes in soils and special landforms in this project. Table 1 lists the Landsat images acquired from two sensors, the Landsat 5 Thematic Mapper (TM) and Landsat 8 Operational Land Imager (OLI). Landsat scenes the Earth Explorer (http://earthexplorer.usgs.gov/) archive were processed by the USGS with Standard Terrain Correction (Level 1T). Level 1T provides systematic radiometric and geometric accuracy by incorporating ground control points while employing a digital elevation map (DEM) for topographic accuracy.

\begin{tabular}{|c|c|c|c|c|}
\hline Landsat Scene Id & Path / Row & Date Acquired & Sun Azimuth & Sun Elevation \\
\hline LT50380361990273XXX03 & 38036 & 30-Sep-90 & 138.15 & 43.71 \\
\hline LT50380371990273XXX02 & 38037 & 30-Sep-90 & 136.87 & 44.6 \\
\hline LT50390361990232XXX03 & 39036 & 20-Aug-90 & 119.48 & 53.35 \\
\hline LT50390371990184XXX03 & 39037 & 3-Jul-90 & 101.23 & 59.61 \\
\hline LT50400361990255XXX01 & 40036 & 12-Sep-90 & 130.44 & 48.45 \\
\hline LT50400371990255XXX01 & 40037 & 12-Sep-90 & 128.83 & 49.17 \\
\hline LT50380362000253XXX02 & 38036 & 9-Sep-00 & 135 & 51.83 \\
\hline LT50380372000253XXX02 & 38037 & 9-Sep-00 & 133.28 & 52.65 \\
\hline LT50390362000260XXX02 & 39036 & $16-$ Sep-00 & 138.25 & 49.99 \\
\hline LT50390372000260XXX02 & 39037 & $16-S e p-00$ & 136.69 & 50.88 \\
\hline LT50400362000235XXX03 & 40036 & 22-Aug-00 & 126.09 & 55.95 \\
\hline LT50400372000235XXX03 & 40037 & 22-Aug-00 & 123.94 & 56.57 \\
\hline LT50380362010248EDC00 & 38036 & $5-S e p-10$ & 137.02 & 54.7 \\
\hline LT50380372010248PAC01 & 38037 & $5-S e p-10$ & 135.16 & 55.57 \\
\hline LT50390362010239EDC00 & 39036 & 27-Aug-10 & 132.62 & 56.93 \\
\hline LT50390372010319PAC01 & 39037 & 15-Nov-10 & 156.46 & 34.74 \\
\hline LT50400362010246EDC00 & 40036 & 3-Sep-10 & 136.06 & 55.22 \\
\hline LT50400372010246EDC00 & 40037 & 3-Sep-10 & 134.16 & 56.06 \\
\hline LC80380362014275LGN00 & 38036 & 2-Oct-14 & 151.75 & 48.03 \\
\hline LC80380372014275LGN00 & 38037 & 2-Oct-14 & 150.55 & 49.16 \\
\hline LC80390362014266LGN00 & 39036 & 23-Sep-14 & 148.47 & 50.91 \\
\hline
\end{tabular}


Page 3 of 7

\begin{tabular}{|l|l|l|l|l|}
\hline LC80390372014282LGN00 & 39037 & 9 -Oct-14 & 152.86 & 46.91 \\
\hline LC80400362014273LGN00 & 40036 & $30-$ Sep-14 & 151.06 & 48.68 \\
\hline LC80400372014273LGN00 & 40037 & $30-$ Sep-14 & 149.83 & 49.8 \\
\hline
\end{tabular}

Table 1: Landsat images list used for the mapping of BSCs.

Image calibration, atmospheric correction, and scene mosaicking were applied to these Landsat scenes before further image transformation and analysis followed methods documented by Potter and $\mathrm{Li}$ [12]. For calibration, the 8-bit satellite-quantized digital numbers (DNs) were converted into top-of-atmosphere (TOA) spectral reflectance using the radiometric gain and offset values associated with the Landsat TM image.

For atmospheric correction, a Fast Line-of-sight Atmospheric Analysis of Spectral Hypercubes (FLAASH) module based on MODTRAN4 in the Environment for Visualizing Images processing software package (ENVI, Research Systems, Inc.) was applied [13]. Atmospheric correction requirements were minimal for these Landsat scenes [14] because aerosol contamination is extremely limited across Southern California desert in the summer months.

\section{Mask layer for mapping BLM lands}

Digital elevation data at 10 -meter spatial resolution were acquired from the National Elevation Dataset (NED) 1/3-arc-second dataset (http://ned.usgs.gov/). A percent slope layer was generated to mask out all areas greater than 13 degrees slope. Non-BLM lands were masked out by using the latest Land Status map (acquired from www.blm.gov/ca/gis) across the DRECP area (Figure 1). The latest road and linear hydrography vectors from the Census Bureau's TIGER (Topologically Integrated Geographic Encoding and Referencing, acquired from https://www.census.gov/cgi-bin/geo/shapefiles2014/ main) database were used to mask out road surfaces and linear water features by buffering 10-meters on both sides of the vector lines. National Agriculture Imagery Program (NAIP) 1-m resolution images for 2012 were next used to calculate the Normalized Difference Vegetation Index (NDVI; as documented by Potter and Li [12]). More than 4000 NAIP digital ortho-quarter quad tiles were processed to mask out the live vegetation pixels. All individual mask layers were consolidated as a single raster layer at 1-meter resolution, with projected coordinate system NAD 1983 California Teale Albers.

\section{BSC index from satellite image analysis}

The BSCI was calculated for each $30-\mathrm{m}$ pixel according to the equation derived by Chen et al. [7]:

$$
\mathrm{BSCI}=(1-\mathrm{L} \times[\text { Red-Green }]) /([\mathrm{Green}+\text { Red }+\mathrm{NIR}] / 3)
$$

Using three Landsat bands, Green, Red, and Near-Infrared (NIR) and the parameter value of $\mathrm{L}$. The Landsat BSCI shows higher values for the presence BSCs, relative to the background of bare sand and dry plant material. The higher the BSC percent coverage, the higher the $\mathrm{BSCI}$ value would be expected.

\section{Results}

\section{Changes in BSC coverage}

BSCI maps generated for the years 1990, 2000, 2010, and 2014 across the Southern DRECP study area in the Lower Colorado Desert (Figure 2) showed the distribution of BSCs at $>33 \%$ Landsat pixel cover, which fell within the BSCI value range of 2.7 to 4.75 . Extensive areas of BSC cover were consistently detected in the USGS-defined drainage basins [15] of the Rice Valley, Big Wash, McCoy Wash, Gypsum Well, Wileys Well, Black Jack Mine, Chuckwalla Spring, Dragon Wash, and Aztec Mines in Eastern Riverside County, Tumco Wash, Picacho Wash, and Indian Wash in Eastern Imperial County and Jojoba Wash, Coyote Wash and Yuha Wash in Western Imperial County.

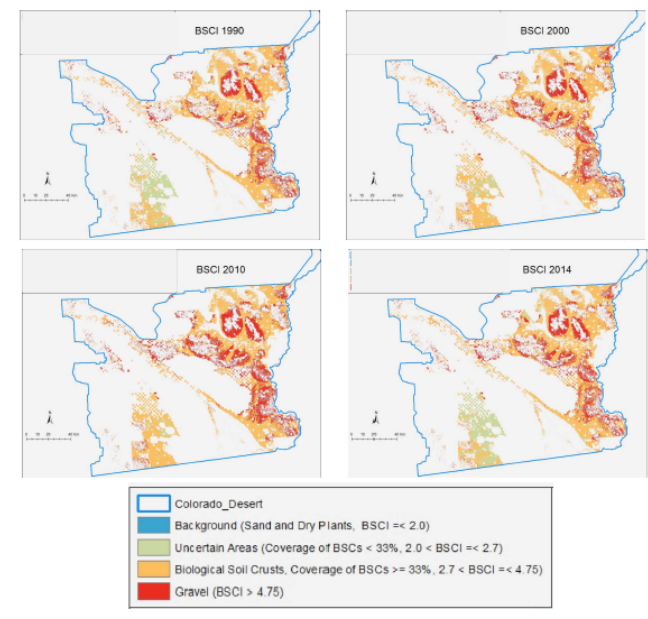

Figure 2: BSCI maps for 1990, 2000, 2010, and 2014 for the Lower Colorado Desert DRCEP area.

A total of $4008 \mathrm{Km}^{2}$ were detected as BSC with $>33 \%$ pixel cover in 1990 across the Colorado Desert area (Figure 3). This BSC coverage category increased by $19 \%$ overall to a total of $4841.7 \mathrm{Km}^{2}$ by 2014 , following a $7.5 \%$ increase in 2000 and a $5.7 \%$ decrease in 2010, relative to 1990 BSC area with $>33 \%$ pixel cover. 


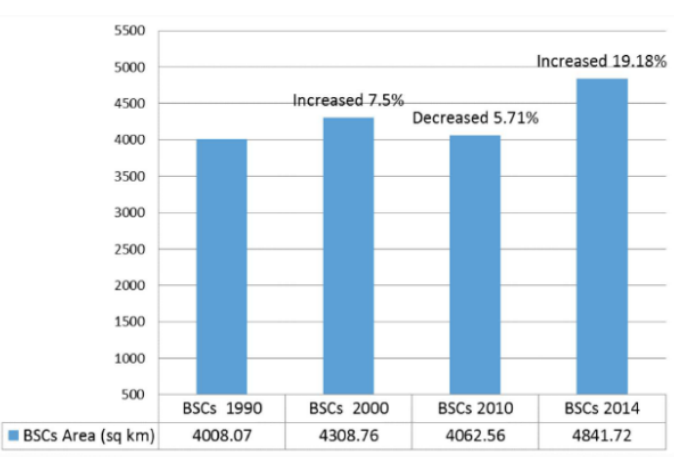

Figure 3: Change in total area of BSCI ( $>33 \%$ pixel coverage) from 1990 to 2014 for the Lower Colorado Desert DRCEP area.

The area of relatively "stable" BSC (i.e., that were also at $>33 \%$ pixel cover in 1990) totaled $3773.6 \mathrm{Km}^{2}$ and $3403.1 \mathrm{Km}^{2}$ in 2000 and 2010 , respectively (Table 2 ).

\begin{tabular}{|l|l|l|l|l|}
\hline & 1990 & 2000 & 2010 & $\mathbf{2 0 1 4}$ \\
\hline 1990 & 4008.07 & & & \\
\hline 2000 & 3773.56 & 4308.76 & & \\
\hline 2010 & 3403.14 & 3870.97 & 4062.56 & \\
\hline 2014 & 3583.36 & 3559.91 & 3234.38 & 4841.72 \\
\hline
\end{tabular}

Table 2: Confusion matrix for BSCI areas $\left(\mathrm{Km}^{2}\right)$ at $>33 \%$ pixel coverage in the Lower Colorado Desert DRCEP area.

In $2014,3583.4 \mathrm{Km}^{2}$ were detected as relatively stable BSC cover. A closer view of relatively stable BSC cover between 2010 and 2014 revealed extensive areas centered on the USGS-defined drainage basins of McCoy Wash, and nearby Gypsum Well and Black Jack Mine in Eastern Riverside County. These extensive areas of relatively "stable" BSC cover were clustered around the main river flow channels of Big Wash and nearby Slaughter Tree Wash and McCoy Wash (Figure 4a). Another notable area where relatively "stable" BSC cover was found clustered around converging dendritic river channels flowing west out of the Granite and Palen Mountains (Figure 4b).

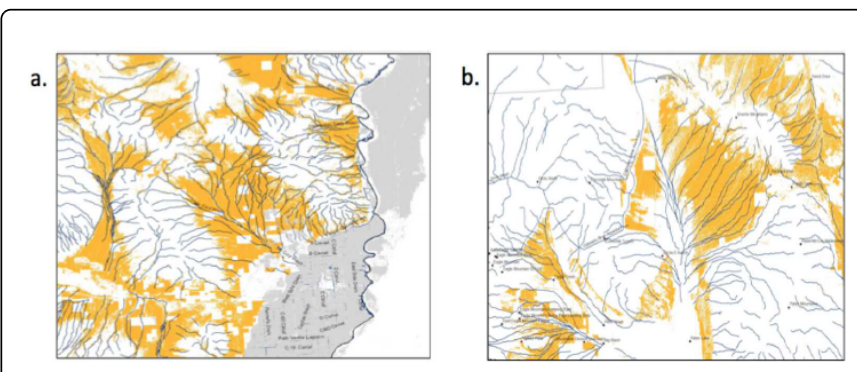

Figure 4: Maps of relatively stable BSC coverage in the (a) McCoy Wash and (b) Palen Mountain areas of East Riverside County.
Data from 2014 showed a net gain from 1990 of 25\% in BSC cover in certain areas and a net loss of $11 \%$ in other areas of the Lower Colorado Desert DRECP area (Figure 5), for a combined change of approximately $15 \%$ gain in BSC cover over that time period. The majority of this total positive change in BSC with $>33 \%$ pixel cover appeared to occur between 2010 and 2014. A closer examination view of positive change in BSC between 2010 and 2014 revealed extensive gain areas in the drainage basins of Rice Valley, Gypsum Well, Granite Mountains, and just north of Interstate 10 around Ford Dry Lake. Conversely, negative changes (losses) of BSC cover between 2010 and 2014 were revealed in limited areas of the drainage basins of Rice Valley, Lower McCoy Wash, and north of Ford Dry Lake.

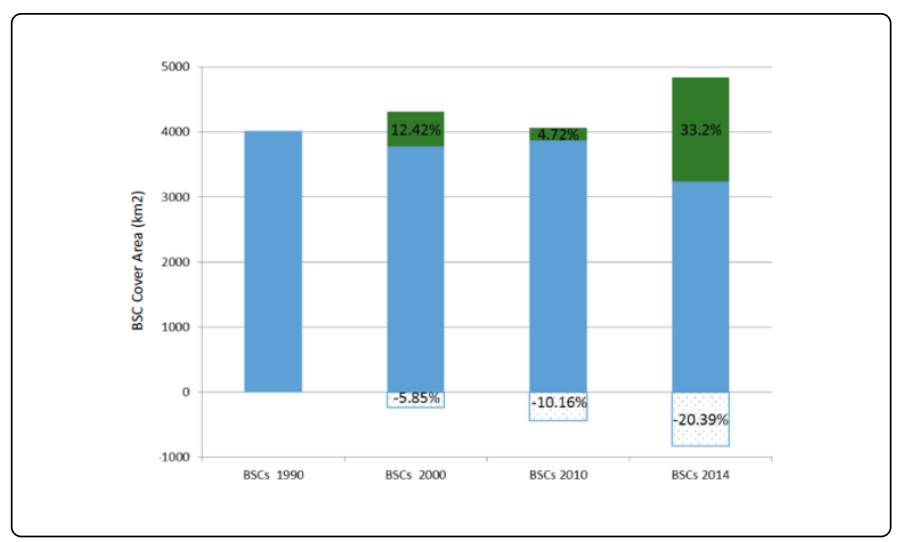

Figure 5: Change in area of BSC ( $>33 \%$ pixel coverage) in 2000, 2010 and 2014. relative to 1990 for the Lower Colorado Desert DRCEP area.

\section{Field validation of BSCI maps}

Ground-truth data collection was conducted in Eastern riverside county in October 2014 to validate the presence of BSCs. A total of 26 sites were visited across the Interstate 10 corridor (Figure 6).

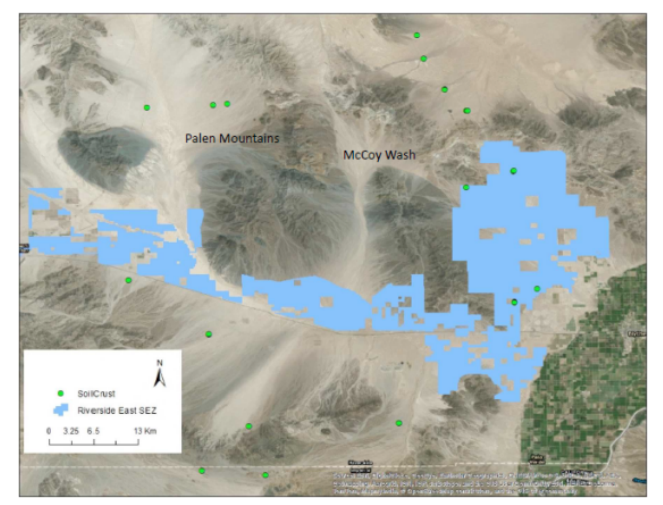

Figure 6: Field validation sites visited in October 2014 in Riverside East County Solar Energy Zones (SEZ).

Results showed that only two of the field sites visited had BSCI values from 2014 that were slightly out of the range set for the likely presence of BSC cover (Table 3). 
Citation: Potter C, Weigand J (2016) Analysis of Changes in Biological Soil Crusts Using Landsat Image Time Series for the Southern California Desert. J Remote Sensing \& GIS 5: 163. doi:10.4172/2469-4134.1000163

Page 5 of 7

\begin{tabular}{|c|c|c|c|c|c|c|c|}
\hline Site ID & Elevation $(\mathrm{m})$ & UTM X (m) & UTM Y (m) & BSCI 1990 & BSCl 2000 & BSCI 2010 & BSCI 2014 \\
\hline 3 & 252.9507 & 660515.3 & 3727860 & 3.45375 & 3.66226 & 3.74341 & 3.4188 \\
\hline 4 & 250.5474 & 660512.1 & 3727858 & 3.45375 & 3.66226 & 3.74341 & 3.4188 \\
\hline 5 & 206.3271 & 670617.5 & 3720007 & 3.72009 & 3.86887 & 4.20023 & 4.01831 \\
\hline 6 & 204.4045 & 670628.5 & 3720024 & 3.90501 & 4.17529 & 4.44876 & 4.24776 \\
\hline 9 & 194.3108 & 694475.5 & 3707331 & 3.64704 & 3.73714 & 4.06605 & 3.71694 \\
\hline 10 & 193.8301 & 694483.1 & 3707335 & 3.64704 & 3.73714 & 4.06605 & 3.71694 \\
\hline 11 & 369.0291 & 678086.7 & 3699345 & 4.1072 & 4.31927 & 4.39968 & 4.44299 \\
\hline 12 & 505.5352 & 670183.4 & 3699807 & 4.14569 & 4.41266 & 4.54797 & 4.53865 \\
\hline 14 & 351.4851 & 675868.3 & 3706478 & 4.17705 & 4.44722 & 4.79402 & 4.476 \\
\hline 18 & 131.8254 & 711277.7 & 3727514 & 3.63116 & 3.80895 & 3.8963 & 3.09119 \\
\hline 23 & 144.5629 & 708439.5 & 3725538 & 3.43269 & 3.5979 & 3.6832 & 3.03961 \\
\hline 25 & 142.4000 & 708469.5 & 3725457 & 3.48233 & 3.58491 & 3.71808 & 3.18198 \\
\hline 26 & 143.8419 & 708421.1 & 3725462 & 3.5138 & 3.6088 & 3.7394 & 3.46659 \\
\hline 28 & 188.0623 & 662408.2 & 3753417 & 2.90058 & 3.13173 & 3.41023 & 2.58853 \\
\hline 29 & 257.0363 & 670551.8 & 3753980 & 3.27889 & 3.53327 & 4.1119 & 3.22933 \\
\hline 31 & 294.2871 & 672328.3 & 3754159 & 3.4357 & 3.52551 & 4.08261 & 3.39236 \\
\hline 32 & 227.9565 & 707900.7 & 3744854 & 3.79933 & 4.05469 & 4.18328 & 3.85834 \\
\hline 35 & 236.6085 & 707929.5 & 3744957 & 4.05012 & 4.1487 & 4.39729 & 3.9992 \\
\hline 38 & 272.8979 & 701878.5 & 3753734 & 3.1035 & 3.29418 & 3.33734 & 3.25013 \\
\hline 39 & 273.3785 & 701959.4 & 3753751 & 3.05047 & 3.26332 & 3.30881 & 3.23399 \\
\hline 40 & 273.3785 & 702057.1 & 3753738 & 3.31555 & 3.51307 & 3.49266 & 3.55517 \\
\hline 42 & 276.0221 & 699137.8 & 3756894 & 2.87257 & 2.94513 & 3.27563 & 2.93138 \\
\hline 43 & 276.2625 & 699106.6 & 3756824 & 2.72593 & 2.77346 & 3.04625 & 2.78087 \\
\hline 44 & 282.0303 & 696473.5 & 3761299 & 3.77311 & 3.92306 & 3.74604 & 3.78546 \\
\hline 45 & 273.1383 & 695509.5 & 3764752 & 2.64783 & 2.9048 & 2.90726 & 2.64377 \\
\hline 46 & 239.4923 & 702155.1 & 3742385 & 4.02327 & 3.94302 & 4.24847 & 3.86839 \\
\hline
\end{tabular}

Table 3: Field site locations visited in October 2014 to verify the presence of BSC cover.

(UTM: NAD 1983 California Teale Albers).

This represented a conservative $92 \%$ accuracy rate for detecting the presence of BSC cover using the Landsat BSCI. Those two locations cited were just slightly outside of the range (but still greater than $\mathrm{BSCI}=2.5$ ) for detecting the presence of BSC, making the practical detection rate close to $100 \%$. It is worth noting that these field site visits were conducted about two months after heavy rainfall events in August 2014. Some of the visited locations showed evidence of lichen BSCs buried by very thin layers of new sediment, along with new growth of herbaceous plant cover nearby (Figure 7). 


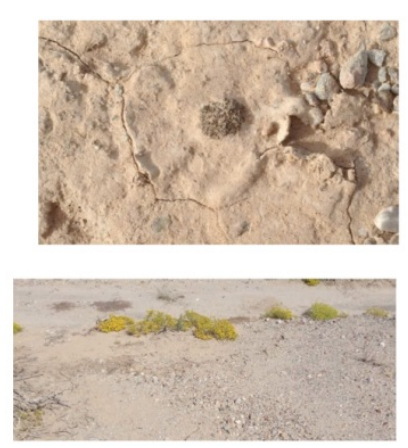

Figure 7: Photographs in October 2014 of soil crust cover in East Riverside County following the heavy rainfall events of August 2014.

\section{Changes in BSC cover after flash flood events}

The proximity of changing areas of BSC cover in 2014 to major river channels implied that flash floods associated with heavily precipitation events could be important agents of change for BSCs. To put 2014 flood events into historical perspective, daily rainfall records from the Iron Mountain $\left(34.15^{\circ} \mathrm{N}, 115.12^{\circ} \mathrm{W}\right)$ and Blythe Airport $\left(33.62^{\circ} \mathrm{N}\right.$, $114.72^{\circ} \mathrm{W}$ ) weather stations (available at www.wrcc.dri.edu) showed that ten dates between 1990 and 2014 had high flash flood potential, i.e., measuring more than $3.8 \mathrm{~cm}$ (1.5 inches) of rain falling in one day. These dates were: September 19, 1991, February 8, 1993; December 25, 1995, September 25, 1997; February 3, 1998; March 6, 2001; February 11, 2005; December 20, 2010; August 4 and 13, 2014. Reports of flash flooding in the county were confirmed around several of these dates in the "Hazard Mitigation" report of 2012 [16].

Comparison of BSCI maps computed for the Landsat image dates of July 21 and October 9, 2014 (pre and post-flash flood events, respectively) suggested that the August 2014 flood events transported gravel-size sediment down most of the lower-elevation washes throughout the Eastern Riverside County area, covering extensive areas formerly detected with BSCs (Figure 8). It is hypothesized from this difference image of BSCI classes (as defined in Figure 2) that surface water runoff during the heavy rainfall events of August 2014 covered extensive areas of the lower McCoy and Palen Valley washes with loose sediment, temporarily covering BSCs in a layer of gravellike material.

\section{Discussion}

Damage to native desert ecosystems in Southern California resulting from solar energy development projects has been speculated to cause negative impacts on biodiversity conservation and greenhouse gas emissions from the disturbance or destruction of desert plant biomass and surface soils $[17,18]$. These same assessment reports have called for as yet unimplemented rigorous survey and statistical analyses that could quantify both internal and external threats to protected Southern California desert ecosystems, essential to assessing vulnerability of landscape sustainability.

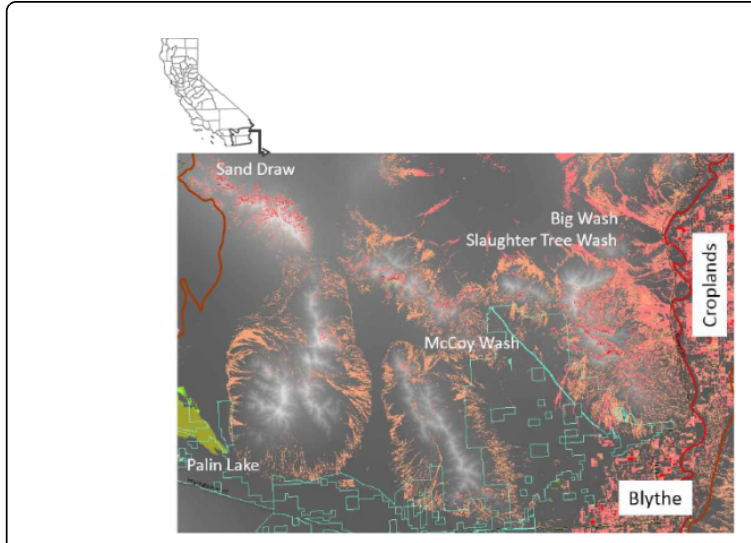

Figure 8: Difference image result of BSCI maps derived from the Landsat image dates of July 21 and October 9, 2014 (pre and postflash flood events, respectively) for Riverside East County Solar Energy Zones (SEZ; outlined in blue). Red shaded pixels indicate change from BSC cover to gravel cover. Shaded elevation was used as the background (darkest shades for the lowest elevations) and Palen Dunes were outlined in the yellow shaded area.

Results from Potter [19] from a 30-year trend analysis of Landsat vegetation index data did not, however, validate that detectable disturbance of vegetation cover (not including BSCs) has yet resulted in adverse ecological impacts to plant communities of the Lower Colorado Desert region, either within Development Focus Areas (DFAs) of Eastern Riverside County or in shrubland areas outside of the DFAs. Instead, plant canopy cover has been relatively stable since the mid-2000s. Subtle changes in vegetation cover in the period after nearly all Southern California solar energy developments were initiated (post 2010, according to Hernandez et al. [17]) could instead be attributed largely to topographic water flow pathways through canyons and desert washes, both in and around the solar energy DFAs.

To begin extending this analysis to include threats to BSC cover, the DFAs delineated as potential footprints of renewable energy development in the DRECP study area were overlaid on BSCIs cover types from 2010 to calculate the areas at risk for disturbance from energy development activities. We estimated that coverage of the forty largest energy development projects planned in the DRECP area could potentially affect more than $10 \mathrm{Km}^{2}$ of BSC cover present as of 2010 .

The overall trends in BSCI classes derived in this study from the past 25 years of satellite image monitoring indicated that the BSC cover category has increased by 15\% overall between 1990 and 2014, with most of this gain occurring during the period after large solar energy developments were initiated (post-2010). The most recent gains in BSC cover were observed primarily around Rice Valley and north of Interstate 10 near around the Palen Mountains. These are washes that include large solar energy DFAs of East Riverside County.

\section{Conclusions}

Although there can be minor reductions locally in the distribution of BSC cover in the Southern California deserts, the overall trend has been an increase in BSC area detected using Landsat image analysis since 1990. Most changes detected in BSC cover between 1990 and 2014 were located in close proximity to known river flow channels such as the Lower McCoy Wash, implying that flash floods associated 
with heavily precipitation events could be the most important agents of change for BSCs in this region.

\section{Acknowledgements}

Satellite image processing and application of BSCI classification algorithms were carried out by Shuang Li of California State University Monterey Bay. The US Department of the Interior Bureau of Land Management funded this study.

\section{References}

1. Belnap J (2006) The potential roles of biological soil crusts in dryland hydrologic cycles. Hydrol Process 20: 3159-3178.

2. Belnap J, Budel B, Lange OL (2003) Biological soil crusts: Characteristics and distribution. In Biological Soil Crusts: Structure, Function, and Management, Belnap J, Lange OL (edn). Springer-Verlag: Berlin 150: 3-30.

3. Belnap J, Miller DM, Bedford DR, Phillips SL (2014) Pedological and geological relationships with soil lichen and moss distribution in the Eastern Mojave Desert, CA, USA. Journal of Arid Environments 106: 45-57.

4. Pietrasiak N, Regus JU, Johansen JR, Lam D, Sachs JL, et al. (2013) Biological soil crust community types differ in key ecological functions. Soil Biology and Diversity 65: 168-171.

5. Pietrasiak N, Johansen JR, Drenovsky RE (2011) Geologic composition influences distribution of microbiotic crusts in the Mojave and Colorado Deserts at the regional scale. Soil Biology and Biochemistry 43: 967-974.

6. Rosentreter R, Bowker M, Belnap J (2007) A Field Guide to Biological Soil Crusts of Western US Drylands. US Government Printing Office, Denver, Colorado.

7. Chen J, Zhang MY, Wang L, Shimazaki H, Tamura M (2005) A new index for mapping lichen-dominated biological soil crusts in desert areas. Remote Sensing of Environment 96: 165-175.

8. DRECP Final EIS (2015) Desert Renewable Energy Conservation Plan (DRECP) and Environmental Impact Report/Environmental Impact Statement, Chapter III.4. Geology and Soils, California Energy
Commission, California Department of Fish and Wildlife, US Bureau of Land Management, US Fish and Wildlife Service.

9. Phillips SJ, Comus PW (2000) A Natural History of the Sonoran Desert. Arizona-Sonora Desert Museum Press, Tucson, and University of California Press, Berkeley.

10. Bunn D, Mummert A, Hoshovsky M, Gilardi K, Shanks S (2006) Chapter 8: Colorado Desert Region, in California Wildlife: Conservation Challenges, California's Wildlife Action Plan, Prepared by the University of California Davis, CA, and the Wildlife Health Center, California Department of Fish and Game, Sacramento, CA.

11. National Park Service (NPS) (2002) Joshua Tree National Park, Nature and Science, Natural Features and Ecosystems: Fan Palm Oases. http:// www.nps.gov/jotr/nature/features/oases/ oases.html.

12. Potter C, Li S (2014) High Resolution Mapping of Soils and Landforms for the Desert Renewable Energy Conservation Plan (DRECP), NASA/ Technical Memorandum, pp: 21857.

13. Adler-Golden SM, Matthew MW, Bernstein LS (1999) Atmospheric Correction for Short-Wave Spectral Imagery Based on MODTRAN4, in Summaries of the Eighth Annual JPL Earth Science Workshop, 1. [http:// makalu.jpl.nasa.gov].

14. Song C, Woodcock CE, Seto KC, Lenney MP, Macomber SA (2001) Classification and Change Detection Using Landsat TM Data: When and How to Correct Atmospheric Effects? Remote Sensing Environment 75: 230-244.

15. Seaber PR, Kapinos FP, Knapp GL (1987) Hydrologic Unit Maps: US Geological Survey Water-Supply Paper 2294, pp: 63.

16. County of Riverside (2012) Multi-Jurisdictional Hazard Mitigation Plan, Riverside, CA, pp: 480.

17. Hernandez RR, Hoffacker MK, Murphy-Mariscal ML, Wu GC, Allen MF (2015) Solar energy development impacts on land cover change and protected areas. Proceedings of the National Academy of Sciences 112: 13579-13584.

18. Hernandez RR, Hoffacker MK, Field CB (2015) Efficient use of land to meet sustainable energy needs. Nature Climate Change 5: 353-358.

19. Potter C (2016) Landsat time series analysis of vegetation changes in solar energy development areas of the Lower Colorado Desert, Southern California, Geoscience and Environment Protection 4: 1-6. 